If you wish to distribute this article to others, you can order high-quality copies for your colleagues, clients, or customers by clicking here.

Permission to republish or repurpose articles or portions of articles can be obtained by following the guidelines here.

The following resources related to this article are available online at wwW.sciencemag.org (this information is current as of September 4, 2014 ):

Updated information and services, including high-resolution figures, can be found in the online version of this article at:

http://www.sciencemag.org/content/345/6201/1153.full.html

Supporting Online Material can be found at:

http://www.sciencemag.org/content/suppl/2014/09/03/345.6201.1153.DC1.html

This article cites $\mathbf{4 5}$ articles, 2 of which can be accessed free:

http://www.sciencemag.org/content/345/6201/1153.full.html\#ref-list-1

This article appears in the following subject collections:

Materials Science

http://www.sciencemag.org/cgi/collection/mat_sci 
did not observe the formation of any well-defined structures in the absence of an applied magnetic field (see, e.g., fig. S8J). 24. A. Dong et al., Nano Lett. 11, 841-846 (2011).

25. S. Brooks, A. Gelman, G. Jones, X.-L. Meng, Handbook of Markov Chain Monte Carlo (Chapman \& Hall, London, 2011).

26. Z. Kakol, R. N. Pribble, J. M. Honig, Solid State Commun. 69 , 793-796 (1989).

27. Ü. Özgür, Y. Alivov, H. Morkoç, J. Mater. Sci. Mater. Electron. 20 789-834 (2009).

28. The formation of helices, and the self-assembly of NCs in our system in general, is likely facilitated by entropic forces; OA used in large excess during self-assembly may act as a depletion agent, inducing crystallization of NCs during hexane evaporation as reported previously (29)

29. D. Baranov et al., Nano Lett. 10, 743-749 (2010).

30. On the basis of measurements of electrophoretic mobility [see (34)] and the lack of literature reports on electric dipole moments of magnetite nanoparticles, we did not consider electrostatic and electric dipole-dipole interactions in our analysis of interparticle interactions. At the same time, we cannot exclude the possible presence of these interactions in our system.
31. S. Srivastava et al., Science 327, 1355-1359 (2010).

32. S. Das et al., Adv. Mater. 25, 422-426 (2013).

33. J. V. I. Timonen, M. Latikka, L. Leibler, R. H. A. Ras, O. Ikkala, Science 341, 253-257 (2013)

34. Previous self-assembly experiments performed in nonpolar solvents excluded a significant role played by electrostatic interactions [e.g., $(35,36)]$. Although the degree of dissociation of $\mathrm{OA}$ in hexane (dielectric constant $=1.84$ ) is negligible, the large excess of $\mathrm{OA}$ as well as the nature of our experimental setup (self-assembly at the liquid-air interface) might potentially promote dissociation of $O A$; to verify this possibility, we used a Malvern Zetasizer Nano ZS to perform electrophoretic mobility $\left(\mu_{\mathrm{e}}\right)$ measurements of our nanocubes in hexane both in the absence and in the presence of additional OA $(5 \% \mathrm{v} / \mathrm{v})$. The results $[0.00706$ $( \pm 0.00104) \times 10^{-4} \mathrm{~cm}^{2} \mathrm{~V}^{-1} \mathrm{~s}^{-1}$ and $0.0218( \pm 0.00710) \times$ $10^{-4} \mathrm{~cm}^{2} \mathrm{~V}^{-1} \mathrm{~s}^{-1}$, respectively] indicate that in both cases, the nanocubes are essentially neutral [compare with (37)]

35. Z. Chen, J. Moore, G. Radtke, H. Sirringhaus, S. O'Brien, J. Am. Chem. Soc. 129, 15702-15709 (2007).
37. S. A. Hasan, D. W. Kavich, J. H. Dickerson, Chem. Commun. 2009, 3723-3725 (2009)

\section{ACKNOWLEDGMENTS}

Supported by Israel Science Foundation grant 1463/11, the G. M. J. Schmidt-Minerva Center for Supramolecular Architectures, and the Minerva Foundation with funding from the Federal German Ministry for Education and Research (R.K.) and by NSF Division of Materials Research grant 1309765 and American Chemical Society Petroleum Research Fund grant 53062-ND6 (P.K.)

\section{SUPPLEMENTARY MATERIALS}

www.sciencemag.org/content/345/6201/1149/suppl/DC1 Materials and Methods

Figs. S1 to S28

References (38-92)

31 March 2014; accepted 14 July 2014

Published online 24 July 2014

$10.1126 /$ science. 1254132

\title{
A fracture-resistant high-entropy alloy for cryogenic applications
}

\author{
Bernd Gludovatz, ${ }^{1}$ Anton Hohenwarter, ${ }^{2}$ Dhiraj Catoor, ${ }^{3}$ Edwin H. Chang, ${ }^{1}$ \\ Easo P. George ${ }^{3,4 *}$ Robert O. Ritchie ${ }^{1,5 *}$
}

High-entropy alloys are equiatomic, multi-element systems that can crystallize as a single phase, despite containing multiple elements with different crystal structures. A rationale for this is that the configurational entropy contribution to the total free energy in alloys with five or more major elements may stabilize the solid-solution state relative to multiphase microstructures. We examined a five-element high-entropy alloy, $\mathrm{CrMnFeCoNi}$, which forms a single-phase face-centered cubic solid solution, and found it to have exceptional damage tolerance with tensile strengths above $1 \mathrm{GPa}$ and fracture toughness values exceeding $200 \mathrm{MPa} \cdot \mathrm{m}^{1 / 2}$. Furthermore, its mechanical properties actually improve at cryogenic temperatures; we attribute this to a transition from planar-slip dislocation activity at room temperature to deformation by mechanical nanotwinning with decreasing temperature, which results in continuous steady strain hardening.

P ure metals rarely display the mechanical properties required for structural applications. Consequently, alloying elements are added to achieve a desired microstructure or combination of mechanical properties, such as strength and toughness, although the resulting alloys invariably still involve a single dominant constituent, such as iron in steels or nickel in superalloys. Additionally, many such alloys, such as precipitation-hardened aluminum alloys, rely on the presence of a second phase for mechanical performance. High-entropy alloys (1-3) represent a radical departure from these notions.

\footnotetext{
${ }^{1}$ Materials Sciences Division, Lawrence Berkeley National Laboratory, Berkeley, CA 94720, USA. ²Department of Materials Physics, Montanuniversität Leoben and Erich Schmid Institute of Materials Science, Austrian Academy of Sciences, Leoben 8700, Austria. ${ }^{3}$ Materials Sciences and Technology Division, Oak Ridge National Laboratory, Oak Ridge, TN 37831, USA. ${ }^{4}$ Materials Sciences and Engineering Department, University of Tennessee, Knoxville, TN 37996 , USA. ${ }^{5}$ Department of Materials Science and Engineering, University of California, Berkeley, CA 94720, USA. *Corresponding author. E-mail: georgeep@ornl.gov (E.P.G.); roritchie@lbl.gov (R.O.R.)
}

As equiatomic, multi-element metallic systems, they contain high concentrations (20 to 25 atomic percent) of multiple elements with different crystal structures but can crystallize as a single phase (4-7). In many respects, these alloys represent a new field of metallurgy that focuses attention away from the corners of alloy phase diagrams toward their centers; we believe that as this evolving field matures, a number of fascinating new materials may emerge.

The CrMnFeCoNi alloy under study here is a case in point. Although first identified a decade ago (1), the alloy had never been investigated mechanically until recently $(5,6,8)$, yet is clearly scientifically interesting from several perspectives. It is not obvious why an equiatomic fiveelement alloy-where two of the elements $(\mathrm{Cr}$ and $\mathrm{Fe}$ ) crystallize with the body-centered cubic (bcc) structure, one (Ni) as face-centered cubic (fcc), one (Co) as hexagonal close-packed (hcp), and one ( $\mathrm{Mn}$ ) with the complex A12 structureshould form a single-phase fcc structure. Furthermore, several of its properties are quite unlike those of pure fcc metals. Recent studies indicate that the alloy exhibits a strong temperature dependence of the yield strength between ambient and cryogenic temperatures, reminiscent of bcc metals and certain fcc solid-solution alloys (6). Strangely, any temperature-dependent effect of strain rate on strength appears to be marginal (6). Moreover, the marked temperature-dependent increase in strength is accompanied by a substantial increase in tensile ductility with decreasing temperature between $293 \mathrm{~K}$ and $77 \mathrm{~K}(6)$, which runs counter to most other materials where an inverse dependence of ductility and strength is invariably seen (9). Preliminary indications suggest that this may be principally a result of the alloy's high work-hardening capability, possibly associated with deformation-induced nanotwinning, which acts to delay the onset of any necking instability (i.e., localized plastic deformation that can lead to premature failure) to higher strains (5).

We prepared the CrMnFeCoNi alloy with highpurity elemental starting materials by arc melting and drop casting into rectangular-cross-section copper molds, followed by cold forging and cross rolling at room temperature into sheets roughly $10 \mathrm{~mm}$ thick. After recrystallization, the alloy had an equiaxed grain structure. Uniaxial tensile specimens and compact-tension fracture toughness specimens in general accordance with ASTM standard E1820 (10) were machined from these sheets by electrical discharge machining. [See (11) for details of the processing procedures, sample sizes, and testing methods.]

Figure 1A shows a backscattered electron (BSE) micrograph of the fully recrystallized microstructure with $\sim 6-\mu \mathrm{m}$ grains containing numerous recrystallization twins. Energy-dispersive $\mathrm{x}$-ray (EDX) spectroscopy and $\mathrm{x}$-ray diffraction (XRD) indicate the equiatomic elemental distribution and single-phase character of the alloy, respectively. Measured uniaxial stress-strain curves at room temperature $(293 \mathrm{~K})$, in a dry ice-alcohol mixture $(200 \mathrm{~K})$, and in liquid nitrogen $(77 \mathrm{~K})$ are plotted in Fig. 1B. With a decrease in temperature from $293 \mathrm{~K}$ to $77 \mathrm{~K}$, the yield strength $\sigma_{\mathrm{y}}$ and ultimate tensile strength $\sigma_{\mathrm{uts}}$ 
increased by $\sim 85 \%$ and $\sim 70 \%$, to 759 and $1280 \mathrm{MPa}$, respectively. Similarly, the tensile ductility (strain to failure, $\varepsilon_{\mathrm{f}}$ ) increased by $\sim 25 \%$ to $>0.7$; the strainhardening exponent $n$ remained high at $\sim 0.4$, such that there was an enhancement in the fracture energy (12) by more than a factor of 2 . Table S1 provides a detailed summary of the stresses and strains at the three different temperatures, as well as the corresponding strain-hardening exponents.

In light of the extensive plasticity involved in the deformation of this alloy, we evaluated the fracture toughness of CrMnFeCoNi with nonlinear elastic fracture mechanics, specifically with crack-resistance curve ( $R$ curve) measurements in terms of the $J$ integral. Analogous to the stress intensity $K$ for linear elastic analysis, provided that specific validity criteria are met, $J$ uniquely characterizes the stress and displacement fields in the vicinity of the crack tip for a nonlinear elastic solid; as such, it is able to capture both the elastic and plastic contributions to the fracture process. $J$ is also equivalent to the strain energy release rate $G$ under linear elastic conditions; consequently, $K$ values can be backcalculated from $J$ measurements assuming a mode I equivalence between $K$ and $J$ : specifically, $J=K^{2} / E^{\prime}$, with $E^{\prime}=E$ (Young's modulus) in plane stress and $E /\left(1-v^{2}\right)$ (where $v$ is Poisson's ratio) in plane strain. $E$ and $v$ values were determined by resonance ultrasound spectroscopy at each temperature (13).
Our toughness results for the CrMnFeCoNi alloy at $293 \mathrm{~K}, 200 \mathrm{~K}$, and $77 \mathrm{~K}$ are plotted in Fig. $1 \mathrm{C}$, in terms of $J_{\mathrm{R}}(\Delta a)$-based resistance curves showing crack extension $\Delta a$ in precracked and side-grooved compact-tension specimens as a function of the applied $J$. Using these $R$ curves to evaluate the fracture toughness for both the initiation and growth of a crack, we measured a crack initiation fracture toughness $J_{\text {Ic }}$, determined essentially at $\Delta a \rightarrow 0$, of $250 \mathrm{~kJ} / \mathrm{m}^{2}$ at $293 \mathrm{~K}$, which in terms of a stress intensity gives $K_{\text {JIc }}=217 \mathrm{MPa} \cdot \mathrm{m}^{1 / 2}$. Despite a markedly increased strength at lower temperature, $K_{\text {JIc }}$ values at $200 \mathrm{~K}$ and $77 \mathrm{~K}$ remained relatively constant at $K_{\text {JIc }}=221 \mathrm{MPa} \cdot \mathrm{m}^{1 / 2}\left(J_{\text {Ic }}=260 \mathrm{~kJ} / \mathrm{m}^{2}\right)$ and $K_{\text {Jc }}=$ $219 \mathrm{MPa} \cdot \mathrm{m}^{1 / 2}\left(J_{\mathrm{Ic}}=255 \mathrm{~kJ} / \mathrm{m}^{2}\right)$, respectively. After
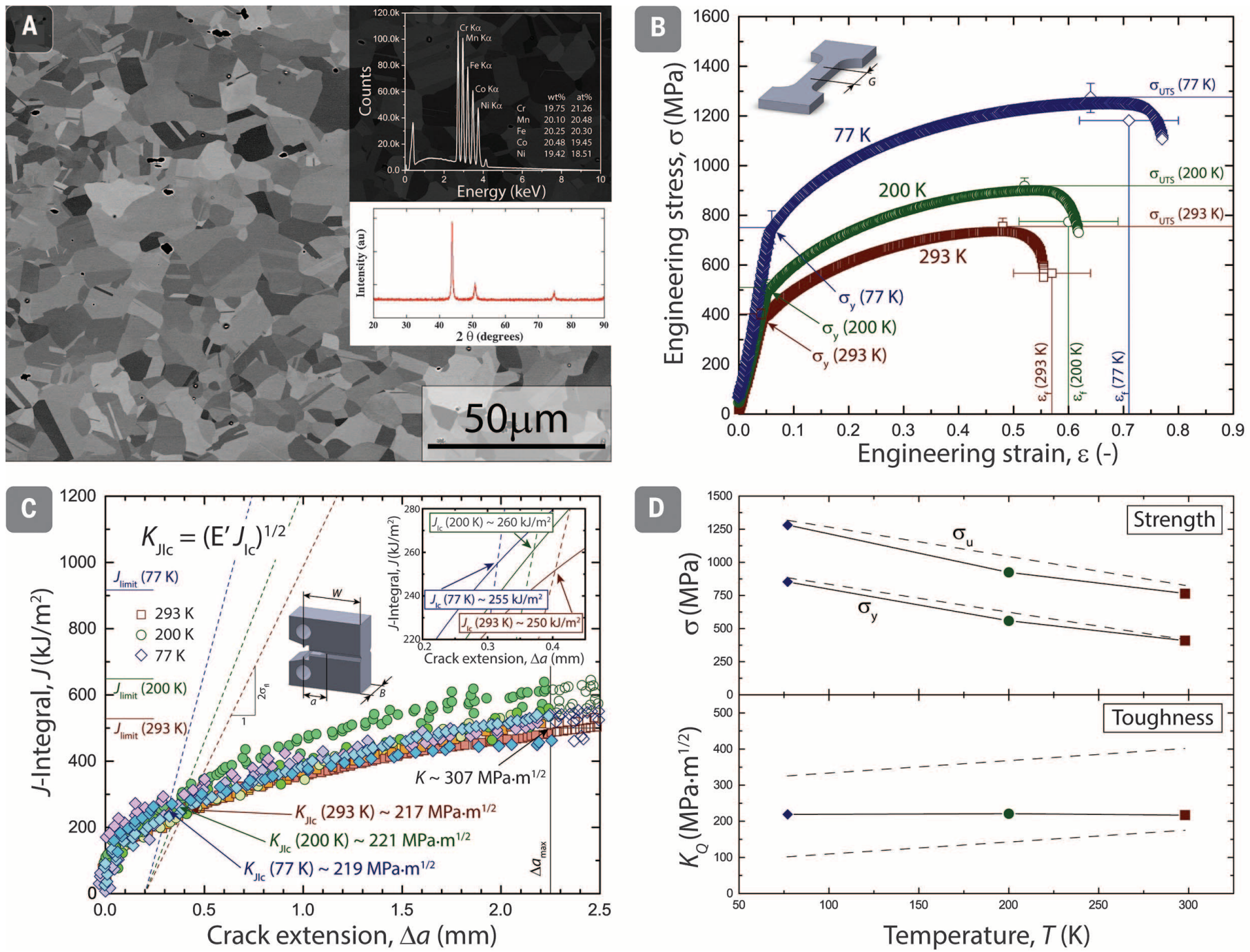

Fig. 1. Microstructure and mechanical properties of the CrMnFeCoNi highentropy alloy. (A) Fully recrystallized microstructure with an equiaxed grain structure and grain size of $\sim 6 \mu \mathrm{m}$; the composition is approximately equiatomic, and the alloy is single-phase, as shown from the EDX spectroscopy and XRD insets. (B) Yield strength $\sigma_{y}$, ultimate tensile strength $\sigma_{u t s}$, and ductility (strain to failure, $\varepsilon_{f}$ ) all increase with decreasing temperature. The curves are typical tests at the individual temperatures, whereas the data points are means \pm SD of multiple tests; see table S1 for exact values. (C) Fracture toughness measurements show $K_{\text {Jlc }}$ values of $217 \mathrm{MPa} \cdot \mathrm{m}^{1 / 2}, 221 \mathrm{MPa} \cdot \mathrm{m}^{1 / 2}$, and $219 \mathrm{MPa} \cdot \mathrm{m}^{1 / 2}$ at

$293 \mathrm{~K}, 200 \mathrm{~K}$, and $77 \mathrm{~K}$, respectively, and an increasing fracture resistance in terms of the $J$ integral as a function of crack extension $\Delta a$ [i.e., resistance curve ( $R$ curve) behavior]. (D) Similar to austenitic stainless steels (e.g., 304, 316, or cryogenic Ni steels), the strength of the high-entropy alloy (solid lines) increases with decreasing temperature; although the toughness of the other materials decreases with decreasing temperature, the toughness of the high-entropy alloy remains unchanged, and by some measures it actually increases at lower temperatures. (The dashed lines in the plots mark the upper and lower limits of data found in the literature.) 
initiation, the fracture resistance further increased with extensive subcritical crack growth; after just over $2 \mathrm{~mm}$ of such crack extension, a crack growth toughness exceeding $K=300 \mathrm{MPa} \cdot \mathrm{m}^{1 / 2}$ $\left(J=500 \mathrm{~kJ} / \mathrm{m}^{2}\right)$ was recorded [representing, in terms of ASTM standards, the maximum (valid) crack extension capacity of our samples]. Such toughness values compare favorably to those of highly alloyed, austenitic stainless steels such as $304 \mathrm{~L}$ and $316 \mathrm{~L}$, which have reported toughnesses in the range of $K_{\mathrm{Q}}=175$ to $400 \mathrm{MPa} \cdot \mathrm{m}^{1 / 2}$ at room temperature (14-16), and the best cryogenic steels such as $5 \mathrm{Ni}$ or $9 \mathrm{Ni}$ steels, with $K_{\mathrm{Q}}=100$ to $325 \mathrm{MPa} \cdot \mathrm{m}^{1 / 2}$ at $77 \mathrm{~K}(17-19)$. Similar to the highentropy alloy, these materials show an expected increase in strength with decreasing temperature to $77 \mathrm{~K}$; however, unlike the high-entropy alloy, their reported fracture toughness values are invariably reduced with decreasing temperature (20) (Fig. 1D) and furthermore are rarely valid (i.e., they are size- and geometry-dependent and thus not strictly material parameters).

The high fracture toughness values of the CrMnFeCoNi alloy were associated with a $100 \%$ ductile fracture by microvoid coalescence, with the extent of deformation and necking behavior being progressively less apparent at the lower temperatures (Fig. 2, A and B). EDX analysis of the particles, which were found inside the voids of the fracture surface and acted as initiation sites for their formation, indicated either Cr-rich or Mn-rich compounds (Fig. 2B, inset). These particles are likely oxides associated with the Mn additions; preliminary indications are that they are absent in the Mn-free (CoCrFeNi) alloy (6). Both microvoid size and particle size varied markedly; the microvoids ranged in size from $\sim 1 \mu \mathrm{m}$ to tens of micrometers, with particle sizes ranging from $<1 \mu \mathrm{m}$ to $\sim 5 \mu \mathrm{m}$ (Fig. $2 \mathrm{~B}$, inset) with an average size of $1.6 \mu \mathrm{m}$ and average spacing $d_{\mathrm{p}} \approx 49.6 \mu \mathrm{m}$, respectively.

To verify the high measured fracture toughness values, we used three-dimensional (3D) stereophotogrammetry of the morphology of these fracture surfaces to estimate local crack initiation toughness $\left(K_{\mathrm{i}}\right)$ values for comparison with the global, ASTM-based $K_{\text {JIc }}$ measurements. This technique is an alternative means to characterize the onset of cracking, particularly under largescale yielding conditions. Under mode I (tensile) loading, the crack surfaces completely separate from each other, with the regions of first separation moving the farthest apart and progressively less separation occurring in regions that crack later. Accordingly, the formation and coalescence of microvoids and their linkage with the crack tip allow for the precise reconstruction of the point of initial crack advance from the juxtaposition of the stereo images of each fracture surface. This enables an evaluation of the crack tip opening displacement at crack initiation, $C T O D_{\mathrm{i}}$, which then can be used to estimate the local stress intensity $K_{\mathrm{i}}$ at the midsection of the sample at the onset of physical crack extension, where $\Delta a=0$ (21). Specifically, we used an automatic fracture surface analysis system that creates 3D digital surface models from stereo-image pairs of the corresponding fracture surfaces taken in the scanning electron microscope (Fig. 2C); digitally reconstructing the crack profiles by superimposing the stereo-image pairs allows for a precise measurement of the $C T O D_{\mathrm{i}} \mathrm{s}$ of arbitrarily chosen crack paths (which must be identical on both fracture surfaces). Figure 2D indicates two examples of the approximately 10 crack paths taken on both fracture surfaces of samples tested at $293 \mathrm{~K}$ and $77 \mathrm{~K}$. The two corresponding profiles show the point at which the first void, formed ahead of the fatigue precrack, coalesced with this precrack to mark the initial crack extension, thereby locally defining the crack initiation event and
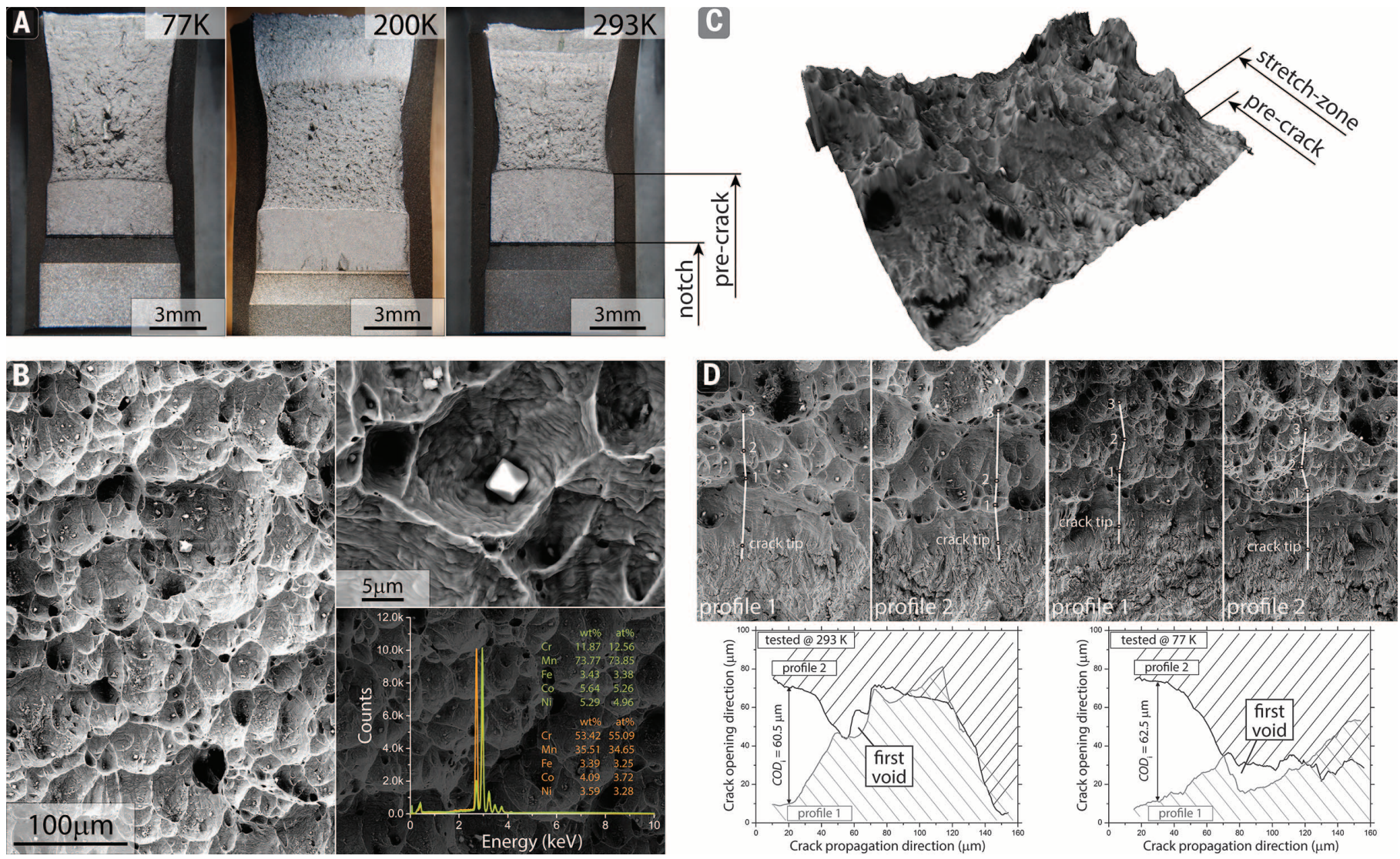

Fig. 2. Images of fractured CrMnFeCoNi samples. (A) Stereomicroscopic photographs of the fracture surfaces after testing indicate less lateral deformation and necking-like behavior with decreasing temperature. (B) SEM image of the fracture surface of a sample tested at room temperature shows ductile dimpled fracture where the void initiation sites are mainly Mn-rich or $\mathrm{Cr}$-rich particles, as shown by the EDX data (insets). (C) Three-dimensional digital fracture

surface models were derived from SEM stereo-image pairs, which indicate the transition from fatigue precrack to ductile dimpled fracture and the presence of the stretch zone. (D) Profiles of identical crack paths from both fracture halves of the fracture surface models were extracted to evaluate the crack tip opening displacement at the first physical crack extension, $C T O D_{i}$, which was then converted to $J_{i}$ using the relationship of the equivalence of $J$ and CTOD (50). 
the fracture toughness (22). Using these procedures, the initial crack tip opening displacements at crack initiation were found to be $C T O D_{\mathrm{i}}=57 \pm 19 \mu \mathrm{m}$ at $293 \mathrm{~K}$ and $49 \pm 13 \mu \mathrm{m}$ at $77 \mathrm{~K}$. Using the standard $J$-CTOD equivalence relationship of $J_{\mathrm{i}} \propto \sigma_{\mathrm{o}} C T O D_{\mathrm{i}}=K_{\mathrm{i}}^{2} / E^{\prime}$ gives estimates of the crack initiation fracture toughness: $K_{\mathrm{i}}=191 \mathrm{MPa} \cdot \mathrm{m}^{1 / 2}$ and $203 \mathrm{MPa} \cdot \mathrm{m}^{1 / 2}$ at $293 \mathrm{~K}$ and $77 \mathrm{~K}$, respectively. These values are slightly conservative with respect to the global $R$ curvebased values in Fig. $1 \mathrm{C}$; however, this is to be expected, as they are estimated at the initial point of physical contact of the first nucleated void with the precrack, whereas the ASTM-based measurements use an operational definition of crack initiation involving subcritical crack extension of $\Delta a=200 \mu \mathrm{m}$.

To discern the micromechanisms underlying the excellent fracture toughness behavior, we further analyzed the fracture surfaces of samples tested at $293 \mathrm{~K}$ and $77 \mathrm{~K}$ by means of stereomicroscopy and scanning electron microcopy (SEM). Some samples were additionally sliced in two halves, embedded, and metallographically pol- ished for BSE microscopy and electron backscatter diffraction (EBSD) analysis of the region in the immediate vicinity of the crack tip and in the wake of the crack, close to the crack flanks, specifically "inside" the sample where fully planestrain conditions prevail.

SEM images of the crack tip region of samples tested at ambient and liquid nitrogen temperatures show the formation of voids and their coalescence characteristic of the microvoid coalescence fracture process (Fig. 3A). A large population of the particles that act as the void
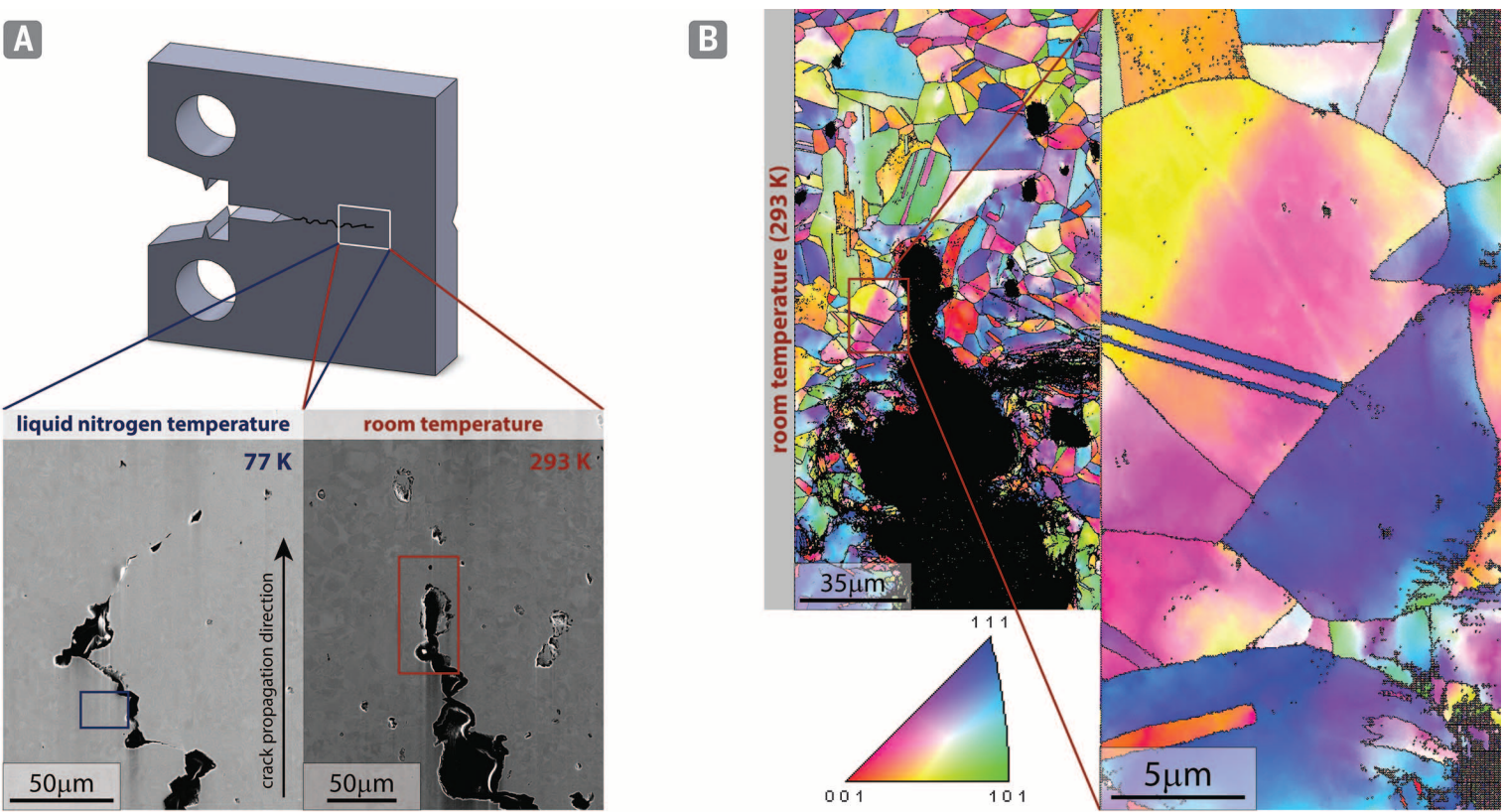

C

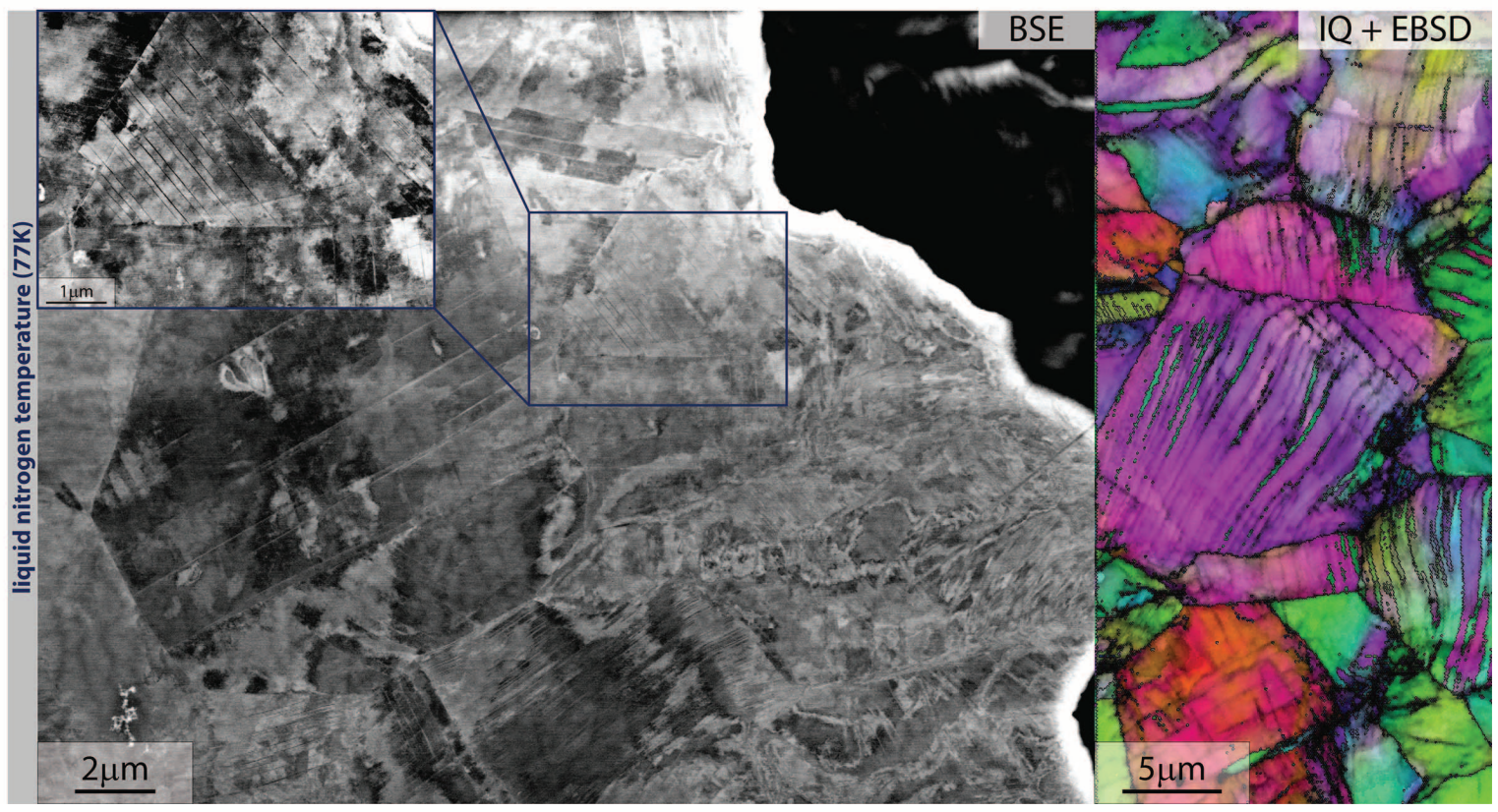

Fig. 3. Deformation mechanisms in the vicinity of the crack tip in the center (plane-strain) section of CrMnFeCoNi high-entropy alloy samples. (A) Low-magnification SEM images of samples tested at $293 \mathrm{~K}$ and $77 \mathrm{~K}$ show ductile fracture by microvoid coalescence, with a somewhat more distorted crack path at the lower temperature. (B) EBSD images show numerous annealing twins and pronounced grain misorientations due to dislocations-the primary defor- mation mechanism at $293 \mathrm{~K}$. (C) At $77 \mathrm{~K}$, BSE images taken in the wake of the propagated crack show the formation of pronounced cell structures resulting from dislocation activity. Both BSE and EBSD images show deformation-induced nanotwinning as an additional mechanism at $77 \mathrm{~K}$. [The EBSD image is an overlay to an image quality (IQ) map, which is a measure of the quality of the collected EBSD pattern used to visualize certain microstructural features.] 
initiation sites can be seen on the fracture surfaces (Fig. 2B); these particles have a substantial influence on material ductility and likely contribute to the measured scatter in the failure strains (Fig. 1B). Macroscopically, fracture surfaces at $77 \mathrm{~K}$ appear significantly more deviated from a mode $\mathrm{I}\left(K_{\mathrm{II}}=0\right)$ crack path than at $293 \mathrm{~K}$ (Fig. 3A). Although such deflected crack paths act to reduce the local crack-driving force at the crack tip (23) and hence contribute to the rising $R$ curve behavior (i.e., crack growth toughness), this mechanism cannot be responsible for the exceptional crack initiation toughness of this alloy. Such high $K_{\mathrm{i}}$ values are conversely derived from the large $C T O D$ s at crack initiation and are associated with the intrinsic process of microvoid coalescence; as such, they are highly dependent on the formation and size of voids, the prevailing deformation and flow conditions, and the presence of steady strain hardening to suppress local necking.

Using simple micromechanical models for fracture (24), we can take advantage of a stress state-modified critical strain criterion for ductile fracture to derive estimates for these high toughness values (25-27). This yields expressions for the fracture toughness in the form $J_{\text {Ic }} \approx \sigma_{0} \bar{\varepsilon}_{\mathrm{f}} l_{0}^{*}$, where $\sigma_{\mathrm{o}}$ is the flow stress, $\bar{\varepsilon}_{\mathrm{f}}$ is the fracture strain in the highly constrained stress state in the vicinity of the crack tip [which is roughly an order of magnitude smaller than the uniaxial tensile ductility (28)], and $l_{0}^{*}$ is the characteristic distance ahead of the tip over which this critical strain must be met for fracture (which can be equated to the particle spacing $d_{\mathrm{p}}$ ). Assuming Hutchinson-Rice-Rosengren (HRR) stressstrain distributions ahead of a crack tip in plane strain for a nonlinear elastic, power-law hardening solid (strain-hardening coefficient of $n$ ) $(29,30)$, and the measured properties, specifically $E, \sigma_{\mathrm{o}}, \varepsilon_{\mathrm{f}}, n, v$, and $d_{\mathrm{p}}$, for this alloy (11), estimates of the fracture toughness of $K_{\text {II }}=\left(J_{\text {Ic }} E^{\prime}\right)^{1 / 2}$ of $\sim 150$ to $215 \mathrm{MPa} \cdot \mathrm{m}^{1 / 2}$ can be obtained for the measured particle spacing of $d_{\mathrm{p}} \sim 50 \mu \mathrm{m}$. Although approximate, these toughness predictions from the critical fracture strain model are completely consistent with a fracture toughness on the order of $200 \mathrm{MPa} \cdot \mathrm{m}^{1 / 2}$, as measured for the CrMnFeCoNi alloy in this study (Fig. 1C).

In addition to crack initiation toughnesses of $200 \mathrm{MPa} \cdot \mathrm{m}^{1 / 2}$ or more, this alloy develops even higher crack growth toughness with stable crack growth at "valid" stress intensities above $300 \mathrm{MPa} \cdot \mathrm{m}^{1 / 2}$. These are astonishing toughness levels by any standard, particularly because they are retained at cryogenic temperatures. A primary factor here is the mode of plastic deformation, which induces a steady degree of strain hardening to suppress plastic instabilities; expressly, the measured strain-hardening exponents of $n \sim 0.4$ are very high relative to the vast majority of metals, particularly at this strength level. Recent studies have shown that, similar to mechanisms known for binary fcc solid solutions $(31,32)$, plastic deformation in the $\mathrm{CrMnFeCoNi}$ alloy at ambient

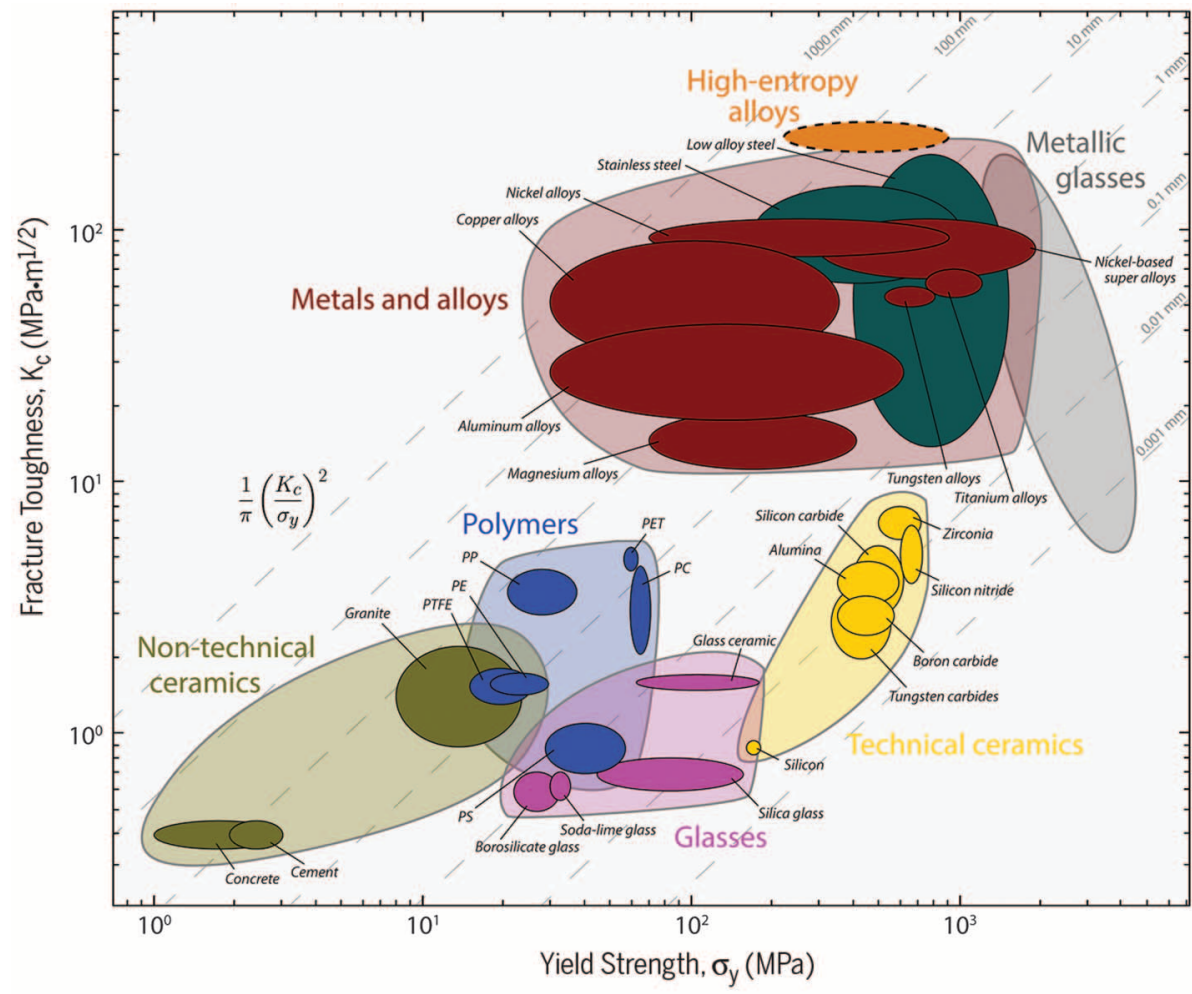

Fig. 4. Ashby map showing fracture toughness as a function of yield strength for high-entropy alloys in relation to a wide range of material systems. The excellent damage tolerance (toughness combined with strength) of the CrMnFeCoNi alloy is evident in that the high-entropy alloy exceeds the toughness of most pure metals and most metallic alloys $(9,49)$ and has a strength comparable to that of structural ceramics (49) and close to that of some bulk-metallic glasses (51-55). temperatures is associated with planar glide of $1 / 2\langle 110\rangle$ dislocations on $\{111\}$ planes leading to the formation of pronounced cell structures at higher strains (5). However, at $77 \mathrm{~K}$, in addition to planar slip, deformation-induced nanoscale twinning has been observed both previously (5) and in the present study (Fig. 3C) and contributes to the increased ductility and strain hardening at lower temperatures. Both the planar slip and nanotwinning mechanisms are highly active in the vicinity of the crack tip during fracture, as illustrated in Fig. 3. EBSD images taken ahead of the crack tip inside the sample of a fracture toughness test performed at room temperature show grain misorientations resulting from dislocation activity as the only deformation mechanism (Fig. 3B). Aside from numerous annealing twins resulting from the recrystallization step during processing, twinning does not play a role at ambient temperatures, with only a few single nanotwins in evidence. With decrease in temperature, cell structure formation is more apparent, as shown by the BSE image in Fig. 3C, taken in the wake of a crack propagating at $77 \mathrm{~K}$. Here, however, excessive deformation-induced nanoscale twinning occurs simultaneously with planar dislocation slip, leading to a highly distorted grain structure, which can be seen in both the BSE and $\mathrm{IQ}+$ EBSD images in the vicinity of the growing crack. [The EBSD image is shown as an overlay of an image quality (IQ) map to enhance visualization of structural deformations of the grains.] Note that several other classes of materials show good combinations of strength and ductility when twinning is the dominant deformation mechanism. These include copper thin films (33-36) and the recently developed twinning-induced plasticity (TWIP) steels (37-40), which are of great interest to the car industry as high-Mn steels (41-44). We believe that the additional plasticity mechanism of nanotwinning in $\mathrm{CrMnFeCoNi}$ is critical to sustaining a high level of strain hardening at decreasing temperatures; this in turn acts to enhance the tensile ductility, which, together with the higher strength at low temperatures, preserves the exceptional fracture toughness of this alloy down to $77 \mathrm{~K}$.

We conclude that the high-entropy CrMnFeCoNi alloy displays remarkable fracture toughness properties at tensile strengths of 730 to $1280 \mathrm{GPa}$, which exceed $200 \mathrm{MPa} \cdot \mathrm{m}^{1 / 2}$ at crack initiation and rise to $>300 \mathrm{MPa} \cdot \mathrm{m}^{1 / 2}$ for stable crack growth at cryogenic temperatures down to $77 \mathrm{~K}$. The alloy has toughness levels that are comparable to the very best cryogenic steels, specifically certain austenitic stainless steels $(15,16)$ and high-Ni steels (17-19, 45-48), which also have outstanding combinations of strength and ductility.

With respect to the alloy's damage tolerance, a comparison with the other major material classes is shown on the Ashby plot of fracture toughness versus yield strength (49) in Fig. 4. There are clearly stronger materials, which is understandable given that $\mathrm{CrMnFeCoNi}$ is a single-phase material, but the toughness of this high-entropy alloy exceeds that of virtually all pure metals and metallic alloys $(9,49)$. 


\section{REFERENCES AND NOTES}

1. B. Cantor, I. T. H. Chang, P. Knight, A. J. B. Vincent, Mater. Sci. Eng. A 375-377, 213-218 (2004).

2. J.-W. Yeh et al., Adv. Eng. Mater. 6, 299-303 (2004).

3. C.-Y. Hsu, J.-W. Yeh, S.-K. Chen, T.-T. Shun, Metall. Mater. Trans. A 35, 1465-1469 (2004).

4. O. N. Senkov, G. B. Wilks, J. M. Scott, D. B. Miracle, Intermetallics 19, 698-706 (2011).

5. F. Otto et al., Acta Mater. 61, 5743-5755 (2013).

6. A. Gali, E. P. George, Intermetallics 39, 74-78 (2013).

7. F. Otto, Y. Yang, H. Bei, E. P. George, Acta Mater. 61 , 2628-2638 (2013).

8. W. H. Liu, Y. Wu, J. Y. He, T. G. Nieh, Z. P. Lu, Scr. Mater. 68 526-529 (2013)

9. R. O. Ritchie, Nat. Mater. 10, 817-822 (2011)

10. E08 Committee, E1820-13 Standard Test Method for Measurement of Fracture Toughness (ASTM International, 2013)

11. See supplementary materials on Science Online.

12. As a preliminary estimate of the fracture resistance, the area under the load displacement curve of a tensile test was used to compute the fracture energy (sometimes termed the work to fracture), which was calculated from this area divided by twice the area of the crack surface.

13. J. Maynard, Phys. Today 49, 26-31 (1996).

14. $K_{Q}$ values refer to fracture toughnesses that are not necessarily valid by ASTM standards (i.e., they do not meet the $J$-validity and/or plane strain conditions). Consequently, these toughnesses are likely to be inflated relative to truly valid numbers and are size- and geometry-dependent; they are not strictly material parameters. When comparing these values to the toughnesses measured in this study for $\mathrm{CoCrFeMnNi}$, it is important to note that all values determined here for the high-entropy alloy were strictly valid, meeting ASTM standards for both $J$ validity and plane strain.

15. W. J. Mills, Int. Mater. Rev. 42, 45-82 (1997).

16. M. Sokolov et al., in Effects of Radiation on Materials: 20th International Symposium, S. Rosinski, M. Grossbeck, T. Allen, A. Kumar, Eds. (ASTM International, West Conshohocken, PA 2001), pp. 125-147

17. J. R. Strife, D. E. Passoja, Metall. Trans. A 11, 1341-1350 (1980)

18. C. K. Syn, J. W. Morris, S. Jin, Metall. Trans. A 7, 1827-1832 (1976).

19. A. W. Pense, R. D. Stout, Weld. Res. Counc. Bull. 205, 1-43 (1975).

20. Note that despite the uncertainty in the (valid) toughness values for the stainless and high Ni steels, their upper toughness range could possibly be higher than the current measurements for the $\mathrm{CrMnFeCoNi}$ alloy. It must be remembered, however, that these materials are microalloyed and highly tuned with respect to grain size/orientation, empering, precipitation hardening, etc., to achieve their mechanical properties, whereas the current $\mathrm{CrMnFeCoN}$ alloy is a single-phase material that undoubtedly can be further improved through second-phase additions and grain control.

21. J. Stampfl, S. Scherer, M. Gruber, O. Kolednik, Appl. Phys. A 63 341-346 (1996)

22. J. Stampfl, S. Scherer, M. Berchthaler, M. Gruber, O. Kolednik, Int. J. Fract. 78, 35-44 (1996)

23. B. Cotterell, J. Rice, Int. J. Fract. 16, 155-169 (1980)

24. R. O. Ritchie, A. W. Thompson, Metall. Trans. A 16, 233-248 (1985).

25. A. C. Mackenzie, J. W. Hancock, D. K. Brown, Eng. Fract. Mech. 9, 167-188 (1977)

26. R. O. Ritchie, W. L. Server, R. A. Wullaert, Metall. Trans. A 10 1557-1570 (1979)

27. Details of the critical strain model for ductile fracture $(25,26)$ and the method of estimating the fracture toughness are described in the supplementary materials.

28. J. R. Rice, D. M. Tracey, J. Mech. Phys. Solids 17, 201-217 (1969).

29. J. W. Hutchinson, J. Mech. Phys. Solids 16, 13-31 (1968).

30. J. R. Rice, G. F. Rosengren, J. Mech. Phys. Solids 16, 1-12 (1968).

31. H. Neuhäuser, Acta Metall. 23, 455-462 (1975)

32. V. Gerold, H. P. Karnthaler, Acta Metall. 37, 2177-2183 (1989).

33. M. Dao, L. Lu, Y. F. Shen, S. Suresh, Acta Mater. 54 5421-5432 (2006).

34. L. Lu, X. Chen, X. Huang, K. Lu, Science 323, 607-610 (2009).

35. K. Lu, L. Lu, S. Suresh, Science 324, 349-352 (2009).
36. A. Singh, L. Tang, M. Dao, L. Lu, S. Suresh, Acta Mater. 59 2437-2446 (2011).

37. R. A. Hadfield, Science 12, 284-286 (1888)

38. V. H. Schumann, Neue Hütte 17, 605-609 (1972)

39. L. Remy, A. Pineau, Mater. Sci. Eng. 28, 99-107 (1977).

40. T. W. Kim, Y. G. Kim, Mater. Sci. Eng. A 160, 13-15 (1993).

41. O. Grässel, G. Frommeyer, C. Derder, H. Hofmann, J. Phys. IV 07, C5-383-C5-388 (1997)

42. 0. Grässel, L. Krüger, G. Frommeyer, L. W. Meyer, Int. J. Plast 16. 1391-1409 (2000)

43. G. Frommeyer, U. Brüx, P. Neumann, ISIJ Int. 43, 438-446 (2003).

44. L. Chen, Y. Zhao, X. Qin, Acta Metall. Sin. Engl. Lett. 26, 1-15 (2013)

45. D. T. Read, R. P. Reed, Cryogenics 21, 415-417 (1981)

46. R. D. Stout, S. J. Wiersma, in Advances in Cryogenic Engineering Materials, R. P. Reed, A. F. Clark, Eds. (Springer, New York, 1986), pp. 389-395

47. Y. Shindo, K. Horiguchi, Sci. Technol. Adv. Mater. 4, 319-326 (2003)

48. J. W. Sa et al., in Twenty-First IEEE/NPS Symposium on Fusion Engineering 2005 (IEEE, Piscataway, NJ, 2005), pp. 1-4.

49. M. F. Ashby, in Materials Selection in Mechanical Design, M. F. Ashby, Ed. (Butterworth-Heinemann, Oxford, ed. 4, 2011), pp. $31-56$.

50. C. F. Shih, J. Mech. Phys. Solids 29, 305-326 (1981).

51. C. J. Gilbert, R. O. Ritchie, W. L. Johnson, Appl. Phys. Lett. 71 476-478 (1997)

52. A. Kawashima, H. Kurishita, H. Kimura, T. Zhang, A. Inoue, Mater. Trans. 46, 1725-1732 (2005)
53. A. Shamimi Nouri, X. J. Gu, S. J. Poon, G. J. Shiflet, J. J. Lewandowski, Philos. Mag. Lett. 88, 853-861 (2008).

54. M. D. Demetriou et al., Appl. Phys. Lett. 95, 041907, 041907-3 (2009)

55. M. D. Demetriou et al., Nat. Mater. 10, 123-128 (2011).

\section{ACKNOWLEDGMENTS}

Sponsored by the U.S. Department of Energy, Office of Science, Office of Basic Energy Sciences, Materials Sciences and Engineering Division. All data presented in this article can additionally be found in the supplementary materials. Author contributions: EP.G and R.OR had full access to the experimental results in the study and take responsibility for the integrity of the data and the accuracy of the data analysis. The alloys were processed by D.C. and mechanically characterized by B.G., A.H., and D.C. Study design, interpretation and analysis of data, and preparation of the manuscript were performed jointly y. B. A.H., D.C. E.H.C., E.P.G., and R.O.R. The authors declare no conflict of interest.

\section{SUPPLEMENTARY MATERIALS}

www.sciencemag.org/content/345/6201/1153/suppl/DC1 Materials and Methods

Supplementary Text

Fig. S1

Table S1

$10.1126 /$ science. 1254581

\title{
CRYSTAL NUCLEATION
}

\section{In situ TEM imaging of $\mathrm{CaCO}_{3}$ nucleation reveals coexistence of direct and indirect pathways}

\author{
Michael H. Nielsen, ${ }^{1,2}$ Shaul Aloni, ${ }^{2}$ James J. De Yoreo ${ }^{3,4}$
}

Mechanisms of nucleation from electrolyte solutions have been debated for more than a century. Recent discoveries of amorphous precursors and evidence for cluster aggregation and liquid-liquid separation contradict common assumptions of classical nucleation theory. Using in situ transmission electron microscopy (TEM) to explore calcium carbonate $\left(\mathrm{CaCO}_{3}\right)$ nucleation in a cell that enables reagent mixing, we demonstrate that multiple nucleation pathways are simultaneously operative, including formation both directly from solution and indirectly through transformation of amorphous and crystalline precursors. However, an amorphous-to-calcite transformation is not observed. The behavior of amorphous calcium carbonate upon dissolution suggests that it encompasses a spectrum of structures, including liquids and solids. These observations of competing direct and indirect pathways are consistent with classical predictions, whereas the behavior of amorphous particles hints at an underlying commonality among recently proposed precursor-based mechanisms.

N ucleation is a key step in the crystallization process, representing the initial transformation of a disordered phase into an ordered one. It is also the most difficult part of the process to observe because it happens on very short time and length scales. In the

$\overline{1}$ Department of Materials Science and Engineering, University of California, Berkeley, CA 94720, USA. ${ }^{2}$ Molecular Foundry, Lawrence Berkeley National Laboratory, Berkeley, CA 94720 USA. ${ }^{3}$ Physical Sciences Division, Pacific Northwest National Laboratory, Richland, WA 99352, USA. ${ }^{4}$ Department of

Materials Science and Engineering, University of Washington, Seattle, WA 98195, USA

*Corresponding author. E-mail: james.deyoreo@pnnl.gov case of electrolyte solutions, there is an open debate as to whether classical nucleation theory (CNT), as initially developed by Gibbs (1), is a suitable framework within which to describe the process, or whether nonclassical elements such as dense liquid phases (2-4) or (meta)stable clusters (5) play important roles. Furthermore, uncertainty exists as to whether a final, stable phase can nucleate directly from solution or whether it forms through a multistep, multiphase evolution $(6,7)$. In the case of multistep nucleation pathways, whether transformation from one phase to another occurs through nucleation of the more stable phase within the 